\title{
LES of Flow Processes in an SI Engine using Two Approaches: OpenFoam and PsiPhi
}

\author{
Nguyen, Minh Thuong; Janas, Peter; Lucchini, Tommaso; D'Errico, Gianluca; \\ Kaiser, Sebastian; Kempf, Andreas
}

This text is provided by DuEPublico, the central repository of the University Duisburg-Essen.

This version of the e-publication may differ from a potential published print or online version.

DOI: https://doi.org/10.4271/2014-01-1121

URN: urn:nbn:de:hbz:464-20180711-085215-2

Link: https://duepublico.uni-duisburg-essen.de:443/servlets/DocumentServlet?id=42262

Legal notice:

Copyright @ 2014 SAE International

Source: This is the authors version of a work that was accepted for publication in SAE Technical Paper 2014-01-1121, 2014. Changes resulting from the publishing process, such as peer review, editing, corrections, structural formatting, and other quality control mechanisms may not be reflected in this document. Changes may have been made to this work since it was submitted for publication. A definitive version was subsequently published in SAE Technical Paper, available online at: https://doi.org/10.4271/2014-01-1121. 
NOTICE: this is the authors version of a work that was accepted for publication in SAE Technical Paper. Changes resulting from the publishing process, such as peer review, editing, corrections, structural formatting, and other quality control mechanisms may not be reflected in this document. Changes may have been made to this work since it was submitted for publication. A defitive version was subsequently published in SAE Technical Paper, doi:10.4271/2014-01-1121

\title{
LES of Flow Processes in an SI Engine using Two Approaches: OpenFoam and PsiPhi
}

\author{
Nguyen, $\mathrm{T}^{1^{*}}$., Janas, P. $^{1}$, Lucchini, T. $^{2}$, D'Errico, G. $^{2}$, Kaiser $^{1}$, S., Kempf, A. ${ }^{1}$ \\ ${ }^{1}$ University of Duisburg Essen \\ ${ }^{2}$ Politecnico di Milano
}

Copyright @ 2014 SAE International

\begin{abstract}
In this study two different simulation approaches to large eddy simulation of spark-ignition engines are compared. Additionally, some of the simulation results are compared to experimentally obtained in-cylinder velocity measurements. The first approach applies unstructured grids with an automated meshing procedure, using OpenFoam and Lib-ICE with a mapping approach. The second approach applies the efficient in-house code PsiPhi on equidistant, Cartesian grids, representing walls by immersed boundaries, where the moving piston and valves are described as topologically connected groups of Lagrangian particles. In the experiments, two-dimensional two-component particle image velocimetry is applied in the central tumble plane of the cylinder of an optically accessible engine. Good agreement between numerical results and experiment are obtained by both approaches.
\end{abstract}

\section{Introduction}

Direct injection, downsizing and advanced combustion modes are key fuel-saving technologies in gasoline engines. To further decrease the fuel consumption and pollutant emissions and to increase the power output, a better understanding of the in-cylinder processes is crucial. Currently, advanced combustion modes cannot be used over the full operating range, often due to turbulence-induced flame quenching or as a result of poor fuel-air mixing near the spark.

Page 1 of 13
In-cylinder phenomena are commonly studied in single-cylinder research engines with optical access for laser diagnostics. On the other hand, engines are investigated by numerical techniques like CFD, which is often less expensive and more flexible than an experiment. As the state of the art, U-RANS simulations are successfully applied by industry to gain an understanding of the engine, but U-RANS will normally fail to predict cyclic variations. A promising alternative are large eddy simulations (LES) that resolve smaller flow structures, enabling them to capture cyclic variations. However, LES is computationally more expensive and requires high-quality meshes on which high-order numerical schemes must be applied. In the context of LES, several CFD codes like AVBP [5,6], KIVA [7], FLUENT [8], or Star-CD [9] have shown at least partial ability to predict some relevant phenomena in internal combustion engines. A critical problem with the application of LES is that any discretization of less than second order accuracy and CFL numbers greater than one lead to artificial dissipation - causing slow mixing, insufficient flame wrinkling, and hence slow flame propagation. Unfortunately, it is very hard to satisfy these accuracy requirements with CFD codes that have been optimized for RANS on unstructured grids.

In this study, two different approaches are compared, which satisfy the stringent requirements for mesh quality and numerical accuracy for the LES of internal combustion engines. Both methods require very limited effort for the grid generation (less than one personnel hour for meshing). The first approach (OpenFOAM) [1] uses unstructured grids with deformable meshes. The second approach (PsiPhi) [2] is based on a structured grid with a combination of Lagrangian particles [3] and 
immersed boundaries [4] to represent the moving parts of the engine. Both codes, OpenFOAM and PsiPhi (in-house, developed at the chair of Fluid Dynamics, University DuisburgEssen) were available without excessive cost for licensing and have demonstrated good parallel scaling, in the case of PsiPhi beyond 4000 cores. So far, the simulations have concentrated on a motored case, for which the velocity fields obtained in both approaches will be compared to each other and to measurements in an optically accessible engine. At the end of the paper, preliminary results are presented for a fired case.

\section{Numerical Methods}

The filtered governing equations for mass (1), momentum (2), and total energy (3) are:

$$
\begin{gathered}
\frac{\partial \bar{\rho}}{\partial t}+\frac{\partial \bar{\rho} \tilde{u}_{i}}{\partial x_{j}}=0 \\
\frac{\partial \bar{\rho} \tilde{u}_{i}}{\partial t}+\frac{\partial \bar{\rho} \tilde{u}_{j} \tilde{u}_{i}}{\partial x_{j}}=-\frac{\partial \bar{p}}{\partial x_{j}}+\frac{\partial \tilde{\sigma}_{i j}}{\partial x_{j}}-\frac{\partial}{\partial x_{j}}\left(\tau_{i j}^{s g s}\right) \\
\frac{\partial \bar{\rho} \tilde{E}}{\partial t}+\frac{\partial \bar{\rho}(\tilde{E}+\bar{p}) \tilde{u}_{j}}{\partial x_{j}}=\frac{\partial}{\partial x_{j}}\left(\kappa \frac{\partial \bar{T}}{\partial x_{j}}\right)+\frac{\partial\left(\tilde{u}_{i} \tilde{\sigma}_{i j}\right)}{\partial x_{j}}-\frac{\partial}{\partial x_{j}}\left(q_{j}^{s g s}\right)
\end{gathered}
$$

where the gas density, the fluid velocity vector, the pressure, and the total energy are represented by $\bar{\rho}, \tilde{u}, \bar{p}$ and $\tilde{E}$, respectively. The temperature and the stress tensor are denoted as $\bar{T}$ and $\tilde{\sigma}_{i j}$. The unresolved stresses $\tau_{i j}^{s g s}$ are computed by the standard Smagorinsky model [10]. The unresolved heat fluxes are represented by $q_{j}^{s g s}$.

The state of the gas is computed by the relations:

$$
p=\rho R T, \quad c_{v}=R / \gamma-1, \quad c_{p}=c_{v}+R
$$

The specific heat capacity at constant pressure and constant volume are indicated by $c_{p}$ and $c_{v}$, respectively.

The total kinetic energy and the stress tensor of a Newtonian fluid can be expressed as:

$$
\begin{gathered}
\bar{\rho} \tilde{E}=\frac{1}{2} \bar{\rho} \tilde{u}_{k} \tilde{u}_{k}+\frac{\bar{p}}{\gamma-1} \\
\tilde{\sigma}_{i j}=\tilde{\tau}_{i j}-\bar{p} \delta_{i j} \\
\tilde{\tau}_{i j}=\mu\left(\frac{\partial \tilde{u}_{i}}{\partial x_{j}}+\frac{\partial \tilde{u}_{j}}{\partial x_{i}}\right)-\frac{2}{3} \mu \frac{\partial \tilde{u}_{k}}{\partial x_{k}}
\end{gathered}
$$

The viscosity of the fluid is calculated from the reference temperature $T_{0}$, the viscosity $\mu_{0}$ at reference temperature, and the Sutherland temperature $T_{s}$ according to the Sutherland law:

$$
\mu(T)=\mu_{0}\left(\frac{T}{T_{0}}\right)^{3 / 2} \frac{T_{0}+T_{s}}{T+T_{s}}
$$

\section{Approach 1: OpenFOAM, unstructured grid}

Codes for unstructured grids - like OpenFOAM - permit the efficient use of body conforming grids to represent complex geometries. In our case, the bottleneck in OpenFOAM is the mesh motion for large valve and piston displacements. The mesh inside the engine has to move according to the motion of the piston and valves without reducing the quality of the mesh. Here, we apply a mapping approach, in which the entire engine cycle $\left(720 \mathrm{CA}^{\circ}\right)$ is split into intervals for which individual grids are used. Within each interval, the mesh maintains high quality while the grid points are moved. At the end of each interval, the results are mapped onto the next grid. This mapping approach has already been tested for U-RANS engine simulations [11] and was developed further with the present meshing procedure. All grids are automatically generated at the start of the simulations and can be reused in later cycles.

\section{Meshing with OpenFOAM}

OpenFOAM's internal automated mesher, snappyHexMesh, is used to generate hexahedral cells. It reads a geometry input file of the engine (Stereo Lithography format - STL) and a block-structured mesh that surrounds the engine geometry, which is then wrapped to the STL geometry. Figure 1 shows the STL representation of the engine with the surrounded block mesh.

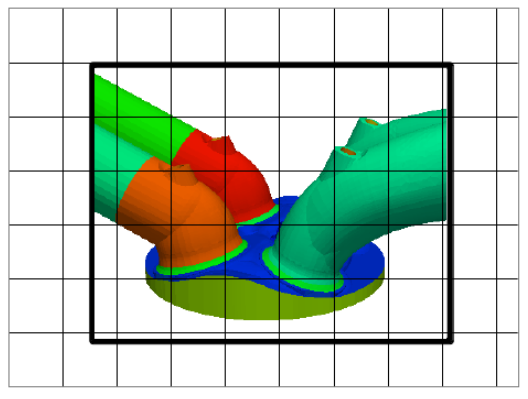

Figure 1: Sketch of the overlapped grid on the STL representation of the engine at top dead center (each color stands for a different patch) -OpenFOAM

The initial grid spacing of the block is $0.5 \mathrm{~mm}$, which is also the biggest cell size in the engine. In order to capture details smaller than $0.5 \mathrm{~mm}$, it is necessary to divide the STL file of the engine in different patches, which can be assigned within snappyHexMesh and used for local refinement. SnappyHexMesh refines the cells in the vicinity of the patch by repeatedly splitting a hexahedral cell into eight cells. The smallest discretized valve gap was set to $0.5 \mathrm{~mm}$; for this position a refinement has been applied twice, leading to a cell size in the valve seat gap of $0.125 \mathrm{~mm}$ as shown in fig. 2. In total, 39 different patches have been created for the STL representation of the engine.

Page 2 of 13 

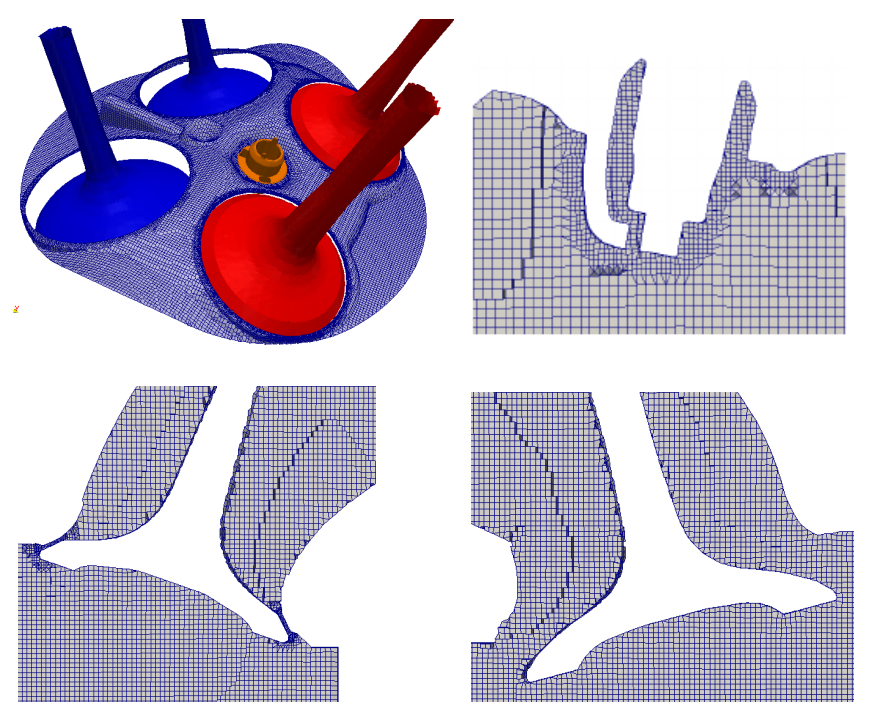

Figure 2: Top left: surface grid of the cylinder head with intake (blue) and exhaust (red) valves. Top right: mesh around the spark plug (cell size $0.25 \mathrm{~mm}$ ) Bottom: cut through the exhaust valve in closed position (cell size inside the gap $0.125 \mathrm{~mm}$, left) and cut through the intake valve at a lift of $5.5 \mathrm{~mm}$ - OpenFOAM

An automated tool for generating STL files for a full cycle has been developed based on Lib-ICE $[12,13,14,15]$ technologies. It reads a STL file of the engine at top dead center (TDC) together with the minimum valve lift position, the valve lift profiles, the stroke, and the connecting-rod length of the engine.

To enforce complete valve closure, either internal walls are added as curtains around the valve seat or the ports are completely detached from the cylinder volume. The former method is computationally less expensive, but cannot resolve the dynamics within the port. For a multi-cycle simulation, the valves should be closed with internal walls, in order to keep track of the flow dynamics in the ports. A total of approximately 100 different grids have been used to represent the intake, compression and expansion stroke. The cell size varied from 5.3 Mio to 0.5 Mio (see figure 3 ).

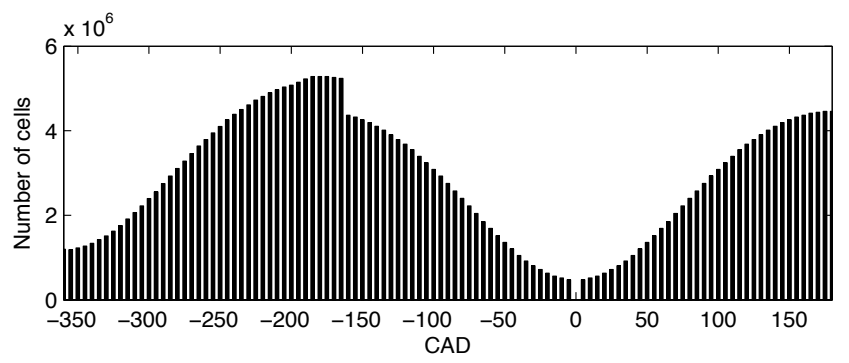

Figure 3: Number of cells used for the intake, compression and expansion stroke (intake port detached at $-160 \mathrm{CA}^{\circ}$ ) OpenFOAM

This meshing approach with OpenFOAM is generic and can be applied to any combustion engine. Furthermore, parts of the engine can be added easily (e.g. the spark plug) or removed (ports, for valve closure). The entire workflow is automated, except for the creation of the basic STL file of the engine. It takes a maximum of one hour on 48 cores to generate the grid for a given interval.

\section{Mesh motion with OpenFOAM}

For the motion of the internal grid points, a Laplace equation is solved for the cell-velocity field [16]. The mesh-motion Laplace equation reads:

$$
\frac{\partial}{\partial x_{i}}\left(\Gamma \frac{\partial u_{c e l l, i}}{\partial x_{i}}\right)=0
$$

where $\Gamma$ is a diffusion constant for the mesh motion field and $u_{\text {cell }}$ is the velocity vector of the cell itself. A time varying boundary condition based on the velocity of the piston and valves is applied for the moving parts. The resolved cellvelocity field is then used to determine the new position of the cell according to the following equation:

$$
\mathrm{x}_{\text {new }}=x_{\text {old }}+u_{\text {cell }} \Delta t
$$

The mesh diffusivity can be constant or dynamic. Here, the diffusion field is decreased near moving boundaries, which creates artificial stiffness, so that cells are less deformed near the moving boundaries.

\section{Numerics with OpenFOAM}

The numerical solver is pressure-based, such that it can handle the coupling of implicitly discretized time-dependent flow equations. For the pressure-velocity coupling the PISOscheme [17] is applied with the following semi-discretized pressure equation [18]:

$$
\frac{\partial \Psi p}{\partial t}+\frac{\partial \Psi p u_{i}}{\partial x_{j}}-\frac{\partial}{\partial x_{j}}\left[\frac{\rho}{\mathcal{A}}\left(\frac{\partial p}{\partial x_{j}}\right)\right]=0
$$

with

$$
\Psi=\frac{\rho}{p} \quad u=\operatorname{diag}(\mathcal{A})(\mathcal{A})^{-1}
$$

where $\mathcal{A}$ represents the coefficient matrix of the linearized algebraic function of the momentum equation (2). The PISO approach permits to use larger time steps once the valves are closed, so that the computational cost is similar to the fully compressible method used in PsiPhi.

The transport equation for the enthalpy $h$ reads:

$$
\frac{\partial(\rho h)}{\partial t}+\frac{\partial(\rho h) u_{i}}{\partial x_{j}}-\frac{\partial}{\partial x_{j}}\left[\alpha_{e f f}\left(\frac{\partial h}{\partial x_{j}}\right)\right]=\frac{\partial p}{\partial t}+u_{i}\left(\frac{\partial p}{\partial x_{j}}\right)
$$

with $\alpha_{\text {eff }}$ as the effective thermal diffusivity accounting for the local mean and turbulent diffusivities.

The flow field is advanced in time by an implicit, second-order backward scheme. The convective scalar fluxes are discretized 
by a TVD scheme, using the Sweby limiter [19]. For the momentum equation, a switch between the CDS and the TVD (Sweby) schemes based on the local Mach number is used: for small valve lifts, the flow in the valve gap can reach high velocities $(\mathrm{Ma}=1)$ introducing numerical instabilities that must be avoided by applying a TVD scheme. At the same time, the TVD scheme would increase numerical dissipation over CDS by a degree that is not acceptable with LES. We achieve a good balance between accuracy and low dissipation by switching from CDS to TVD wherever the Mach number exceeds 0.5. The effect is illustrated by fig. 4 , showing the maximum Mach number over the crank angle for the intake stroke: in the interval between $-390 \mathrm{CA}^{\circ}$ and $-385 \mathrm{CA}^{\circ}$, very high velocities occur in the small valve gap of $0.5 \mathrm{~mm}$. It can be seen that the CDS scheme causes strong spikes, whereas the CDS-TVD scheme gives a smoother time course of the velocity inside the valve gap.

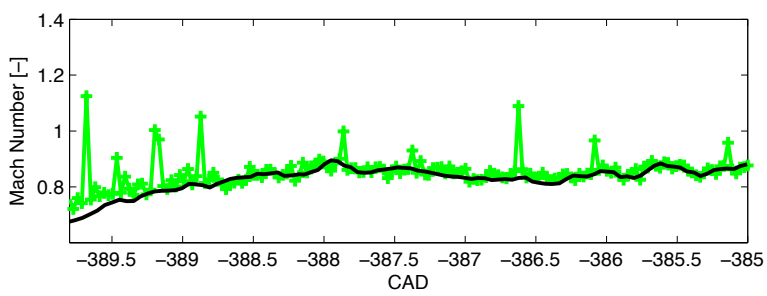

Figure 4: Plot of the maximum Mach number during the intake stroke $\left(-390 \mathrm{CA}^{\circ}\right.$ to $\left.-385 \mathrm{CA}^{\circ}\right) ;(-+-)$ : CDS for the momentum equation, (-): CDS-TVD scheme for the momentum equation OpenFOAM

\section{Approach 2: PsiPhi, immersed boundaries}

In this approach, the immersed-boundary technique is employed for the representation of the complex geometry of the engine. First, volumetric pixels (voxels) of different 3D engine components are generated from the corresponding 3D CAD models of the cylinder, the intake port, the outlet port and the cylinder head. These voxels are then mapped to the main Cartesian equidistant grid to build the immersed boundaries of the simulated engine. This approach yields high numerical accuracy, permits more cells, promises high model accuracy (isotropic cells), and ensures that finer grids are maintained in the region of the flame, while being cheaper at the same CFL number.

The method is available in the in-house code PsiPhi, which has been developed to combine high computational accuracy, good parallel scaling and high efficiency on state of the art computer hardware. Focusing on the LES of combustion, PsiPhi has proven its abilities in simulations of fully premixed, partially premixed and non-premixed flames [20,2,21,22] of gas jets [23], and pulverized coal [24].

\section{Mesh generation with PsiPhi}

Mesh generation in PsiPhi is simple, flexible, and fast. It takes less than an hour to generate any computational grid with high resolution from the CAD model, for ten to hundreds of millions of cells. The generated voxels from the moving parts including the piston, the intake and exhaust valves are used to create

Page 4 of 13 the different groups of particles that describe the moving objects. Figure 5 shows engine valves meshed with this method. Note that the sharp voxel-edges and voxel-corners displayed in fig. 5 are not "seen" by the simulation. The stairs are only a result of the graphical representation of the cells; they do not induce any flow over a stair-like surface (the stairs can be considered as a first order approximation of the flat boundary).

The following section is dedicated to the moving-boundary technique that is applied within this study. With this approach, the simulated engine can be decomposed into structured cubic domains that are highly effective for parallelization.

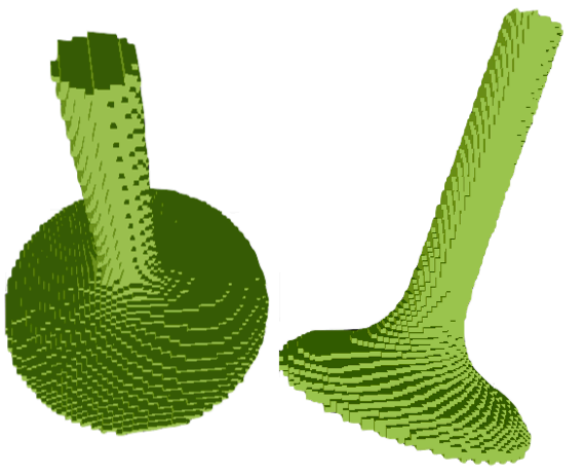

Figure 5: The intake and exhaust valves are represented by Lagrangian particles and mapped to voxels on the computational grid $(0.5 \mathrm{~mm}$ cell size $)$ - PsiPhi

\section{Moving boundaries with PsiPhi}

Coupled to the immersed boundary method, a mesh-free approach is employed to handle the moving boundaries of the engine simulation. Moving parts like the piston and the valves are formed by different groups of Lagrangian particles. These particles are controlled by the same law of motion as the corresponding moving objects. Using this method, no mesh alteration is required, which avoids the difficulty involved in the generation of high quality moving meshes.

In this mesh-free technique, the momentum equation is modified to account for the particle force $(F p)$ that is used to impose the flow condition at the boundary of any moving objects. The resulting momentum equation reads:

$$
\frac{\partial \bar{\rho} \tilde{u}_{i}}{\partial t}+\frac{\partial \bar{\rho} \tilde{u}_{j} \tilde{u}_{i}}{\partial x_{j}}=-\frac{\partial \bar{p}}{\partial x_{j}}+\frac{\partial \tilde{\sigma}_{i j}}{\partial x_{j}}-\frac{\partial}{\partial x_{j}}\left(\tau_{i j}^{s g s}\right)+F p
$$

Calculating the particle force $F p$ requires the imposed velocities and the imposed pressure at the boundary between the solid phase and the gas phase. These velocities and pressure are computed from the particle velocity $V p_{i}$ and the velocity of neighboring fluid cells $V f_{i}$ [3]:

$$
V s_{i}=2 V p_{i}-V f_{i}
$$

In the case of more than one neighboring fluid cell, the velocity of a solid cell is computed from the particle velocity $V p_{i}$ and the average of the neighboring fluid cells: 


$$
V s_{i}=2 V p_{i}-\frac{\sum_{j}^{N b} V f_{i j}}{N b}
$$

The pressure of the solid cells at the boundary can be computed based on the pressure gradient that is calculated from the density $\rho$ of the neighboring fluid cell and the acceleration of the particle $a_{p i}$ [3]:

$$
\frac{\partial p}{\partial x_{i}}=-\rho a_{p i}
$$

With more neighboring fluid cells, the pressure gradient of the solid cell can be evaluated:

$$
\frac{\partial p}{\partial x_{i}}=-\frac{\sum_{j}^{N b} \rho_{j}}{N b} a_{p i}
$$

Where $\rho_{j}$ is the density of the neighboring fluid cell $\mathbf{j}$ and $\mathrm{Nb}$ denotes the number of the neighboring fluid cells.

In this approach, the activation and deactivation of the mesh cells are handled by the flux-blended scheme, which is a combination between the upwind and the central differencing scheme. When the cell changes from solid to fluid, a linear interpolation scheme with weighting factors is used to create the history in the fresh cleared cells from the momentum of the neighboring fluid cells.

\section{Non-reflecting boundary conditions}

In compressible flow, the truncated inlet or outlet usually leads to numerical oscillations resulting from the spurious waves, since the physical boundary conditions are not known in detail. In engine simulations, correctly imposing the physical boundary conditions would require to include the long intake and exhaust ports, which would increase the computational effort by a considerable amount. In this study, the inlet and outlet ports are kept short, and Navier-Stokes characteristic boundary conditions (NSCBC) were implemented to compute the numerical conditions on the inlet and outlet planes. The amplitude variations of the incoming and outgoing waves were determined from the "Local One-Dimensional Inviscid (LODI) relations" for the primitive variables at the boundary [25].

\section{Engine Geometry}

The single cylinder gasoline direct injection engine of the Institute for Combustion and Gas Dynamics (University of Duisburg-Essen) features four valves and a pent-roof head. It provides optical access through the piston crown and the cylinder liner. Table 1 shows the key specifications of the engine.

\begin{tabular}{|l|l|}
\hline Displacement & $499 \mathrm{~cm}^{3}$ \\
\hline Stroke & $90 \mathrm{~mm}$ \\
\hline Bore & $84 \mathrm{~mm}$ \\
\hline Connecting rod length & $161 \mathrm{~mm}$ \\
\hline Compression ratio & $10: 1$ \\
\hline Number of valves & 4 \\
\hline Exhaust valve open & $180 \mathrm{CA}^{\circ}$ \\
\hline
\end{tabular}

Page 5 of 13

\begin{tabular}{|l|l|}
\hline Exhaust valve closed & $400 \mathrm{CA}^{\circ}$ \\
\hline Intakevalve open & $-405 \mathrm{CA}^{\circ}$ \\
\hline Intakevalve closed & $-145 \mathrm{CA}^{\circ}$ \\
\hline
\end{tabular}

Table 1: Specification of the engine. Top dead center (TDC) of the compression stroke is taken to be zero degrees crankangle $\left(0 \mathrm{CA}^{\circ}\right)$.

Pressure is measured by crank-angle-resolving sensors. Piezoresistive sensors determine the pressure in the intake and exhaust ports $100 \mathrm{~mm}$ upstream of the valves, and a piezoelectric one the relative in-cylinder pressure near the spark-plug location. The in-cylinder pressure was pegged to the absolute intake pressure at a position near bottom dead center (BDC).

\section{Measurements}

The engine was motored at a speed of $1000 \mathrm{rpm}$; intake, coolant and oil temperatures were kept at $333 \mathrm{~K}$. The maximum intake valve lift was $7 \mathrm{~mm}$ at $-270 \mathrm{CA}^{\circ}$, while the maximum exhaust valve lift was $3.5 \mathrm{~mm}$ at $280 \mathrm{CA}^{\circ}$.

The instantaneous velocity field in the tumble symmetry plane was measured by particle image velocimetry (PIV). Figure 6 illustrates the optical access through a quartz cylinder and a quartz window in the piston crown. This results in a view of about $60 \mathrm{~mm}$ width, extending about $30 \mathrm{~mm}$ down from the fire deck.
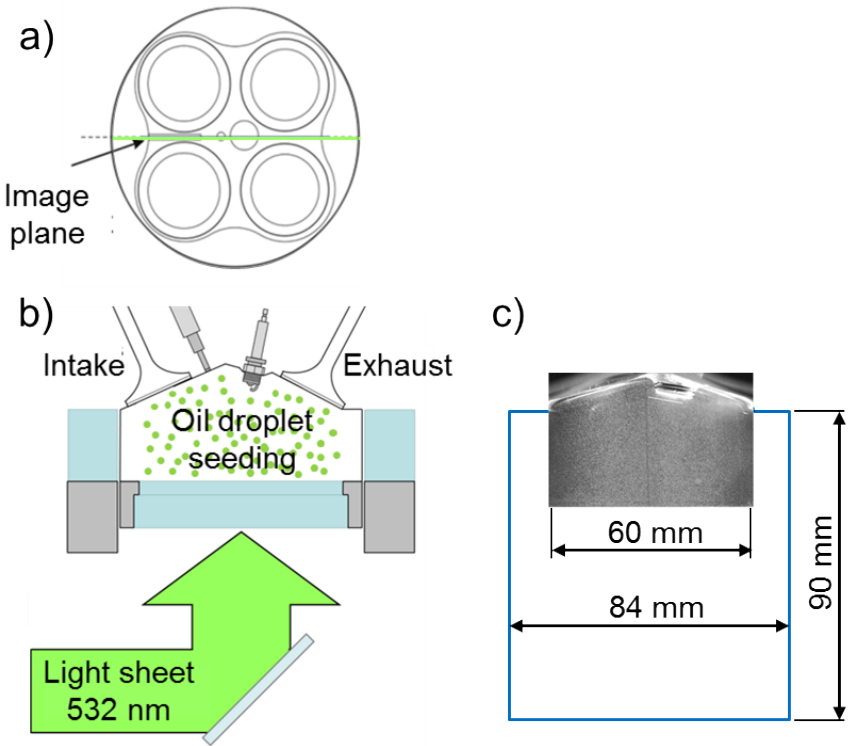

Figure 6: (a) bottom view of the engine head, (b) side view of the head, cylinder and measurement domain, (c) field of view and dimensions of the cylinder.

The intake-air was mixed with silicon-oil droplets (nominal diameter $0.2 \mu \mathrm{m}-0.3 \mu \mathrm{m}$ ) in a chamber $500 \mathrm{~mm}$ upstream of the intake valves. The particles were illuminated with a doublepulsed Nd:YAG laser at $532 \mathrm{~nm}$. The laser light sheet with a thickness of $0.9 \mathrm{~mm}$ was directed into the engine via a mirror in the bottom of the slotted, extended piston. The light scattered from the particles was detected by a double-frame CCD camera; each image pair was processed by LaVision Davis 7.2 to 
provide a two-dimensional velocity vector map. Spurious vectors were removed using standard validity checks [26]. At selected crank angles $(-180,-140,-120,-90) 100$ shots each were taken of the velocity field to be used for the validation of the two simulation approaches.

\section{Simulation Setup}

In both approaches the crevice volume between the liner and the piston is neglected, as well as a chamfer between the glass liner and cylinder head. To compensate for these crevice volumes, the clearance height at TDC was increased by $2.6 \mathrm{~mm}$. In OpenFOAM with its body-fitted mesh, the minimum valve gap was chosen to $0.5 \mathrm{~mm}$ with a grid spacing of $0.125 \mathrm{~mm}$ within this gap. In the second approach, PsiPhi, the valve gap was resolved by the same $0.5 \mathrm{~mm}$ cells that were used throughout the domain. Table 2 and fig. 7 show the computational domains and key parameters for both approaches.

\begin{tabular}{|l|l|l|l|}
\hline Approach & $\begin{array}{l}\text { Mesh } \\
\text { type }\end{array}$ & $\begin{array}{l}\text { Grid } \\
\text { spacing }\end{array}$ & Number of cells \\
\hline $\begin{array}{l}\text { Unstructured } \\
\text { (OpenFOAM) }\end{array}$ & $\begin{array}{l}\text { Body } \\
\text { fitted }\end{array}$ & $\begin{array}{l}0.125- \\
0.5 \mathrm{~mm}\end{array}$ & $\begin{array}{l}\text { BDC: } 5.3 \text { Mio (with inta... } \\
\text { TDC: }\end{array}$ \\
\hline $\begin{array}{l}\text { Structured } \\
\text { (PsiPhi) }\end{array}$ & $\begin{array}{l}\text { Block } \\
\text { structured }\end{array}$ & $0.5 \mathrm{~mm}$ & $\begin{array}{l}\text { BDC: } \\
\text { TDC: } 0 \\
\text { Total: } 9 \\
\text { C }\end{array}$
\end{tabular}

Table 2: Grid specification of the two approaches a)

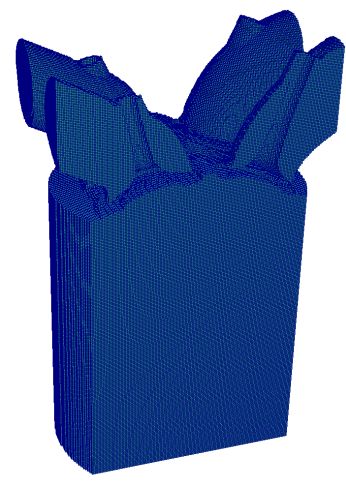

b)

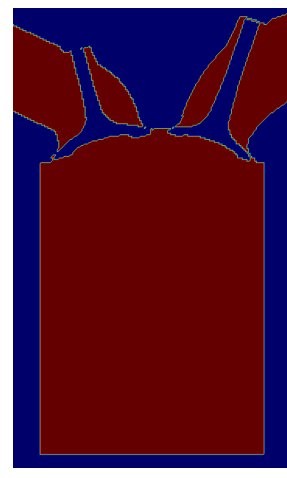

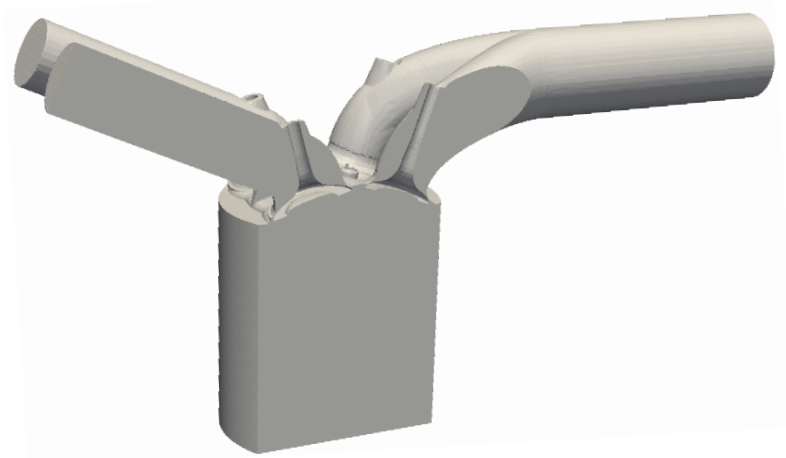

Figure 7: (a) Fluid cells at BDC for the immersed boundary approach, (b) Cut through the domain of the immersed boundary approach at BDC, red: fluid cells, blue: solid cells, (c)
Computational domain of the unstructured approach (body fitted grid), left intake, right exhaust port.

\section{Boundary conditions}

The simulations were started at $-360 \mathrm{CA}^{\circ}$. At this position, the intake valves are already opened with a lift of $1.3 \mathrm{~mm}$ and the exhaust valves are about to close $(0.26 \mathrm{~mm})$. Because both approaches have a physical minimum valve gap of around 0.5 $\mathrm{mm}$, the valve overlap was not taken into account here. In both approaches, the walls are treated as adiabatic with a no-slip condition applied. The intake valve closure was set to -160 $\mathrm{CA}^{\circ}$.

The velocity field for the first approach (OpenFOAM) was initialized as stagnant, for the second approach (PsiPhi) with artificial fluctuations smaller than $6 \mathrm{~m} / \mathrm{s}$. All other scalar variables were initialized uniformly within the entire domain. The temperature was set to $333 \mathrm{~K}$ and a pressure of $1.0165 \mathrm{bar}$ was imposed, which was taken from the absolute intake pressure measurement. With the first approach (OpenFOAM), the measured pressure profile was imposed on the intake. With the second approach, the NSCBC [25] were applied, in which the inlet velocities are computed from the estimated time dependent mass flow and the imposed intake pressure is solved directly from the amplitudes of the characteristic waves coming into the computational domain.

\section{Results}

Simulations were carried out to compare the capabilities of the two approaches. The results are compared to the velocity measurements. Table 3 shows the computational effort required for the intake, compression, and expansion stroke.

\begin{tabular}{|l|l|l|}
\hline Approach & OpenFOAM & PsiPhi \\
\hline Number of CPUs & 96 & 192 \\
\hline CFL number & 1.0 & 0.3 \\
\hline Delta t min [s] & $0.7 \mathrm{e}-6$ & $0.34 \mathrm{e}-6$ \\
\hline Delta t max [s] & $2.75 \mathrm{e}-5$ & $0.56 \mathrm{e}-6$ \\
\hline Calculation time & 9 days & 10 days \\
\hline
\end{tabular}

Table 3: Simulation effort for intake, compression and expansion stroke

As a result of the meshing scheme, in the PsiPhi approach the total number of cells is fixed during the entire simulation, whereas it is varying with the OpenFOAM approach, such that the number of CPUs also can be varied.

In figure 8, the in-cylinder pressure is plotted over the intake stroke. The calculated pressure is sampled near the spark plug location and compared to the measurements. The simulations were initialized with the measured intake pressure, which leads to a deviation of $50 \mathrm{mbar}$ at $-360 \mathrm{CA}^{\circ}$ relative to the measured in-cylinder pressure. The simulated pressure curves are matching each other after $45 \mathrm{CA}^{\circ}$. Beyond this point, the simulated pressure curves divert and coincide again at $-180 \mathrm{CA}^{\circ}$ 
(BDC). This deviation is expected from the different strategies for setting the boundary conditions at the intake port since OpenFOAM uses a time-varying pressure and PsiPhi employs non-reflecting boundary conditions.

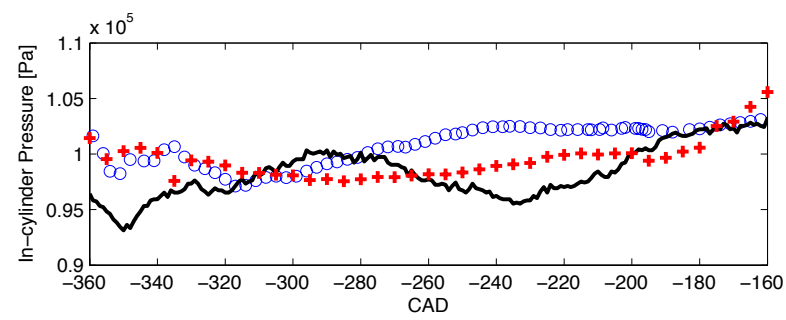

Figure 8: In-cylinder pressure during the intake strokeuntil IVC $\left(-160 \mathrm{CA}^{\circ}\right)$ measurement (-),OpenFOAM (o), PsiPhi (+).

At the time of the intake valve closure $\left(-160 \mathrm{CA}^{\circ}\right)$, the incylinder pressure from both simulations match the measured in-cylinder pressure. From this crank angle on, the piston compresses the air inside the cylinder. Figure 9 shows the incylinder pressures during the compression stroke. The small deviation of the pressure for the compression and expansion stroke may be related to the specific heat capacities and to the adiabatic boundary conditions. PsiPhi assumes constant heat capacity, while in OpenFOAM the heat capacity is a function of the temperature. The peak pressure computed with the first approach (OpenFOAM) is 25.4 bar, with the second approach (PsiPhi) it is 24.9 bar.

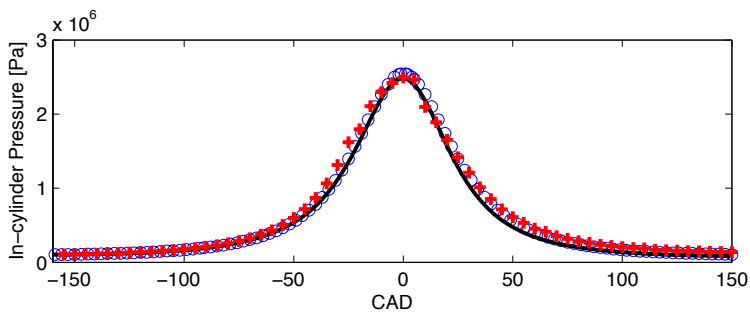

Figure 9: In-cylinder pressure during compression and expansion (measurement (-), OpenFOAM (O), PsiPhi (+))

The in-cylinder gas temperature was computed from the measured pressure trace by the polytropic relation of an adiabatic system for air and compared to the temperature obtained from the simulations. Figure 10 shows good agreement between the simulated in-cylinder temperatures and the calculated polytropic temperature. However, matching a motored pressure trace is certainly not a very stringent test of the validity of the simulations, hence more detailed results will be examined in the following.

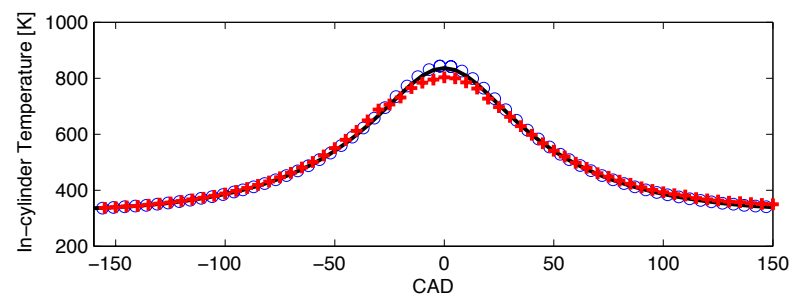

Figure 10. In-cylinder temperature during compression and expansion (Polytropic relation for temperature (-), OpenFOAM (o), PsiPhi (+))

\section{Simulation results}

The velocity fields for the z-component at $-310 \mathrm{CA}^{\circ}\left(50 \mathrm{CA}^{\circ}\right.$ after the start of the simulation) are shown for both approaches in fig.11. The velocity profiles are sampled $20 \mathrm{~mm}$ below the cylinder head. Similar flow patterns in the two simulations throughout the intake stroke can be related to the high velocity flow through the valve gap, where most of the turbulence is generated, dominating the surrounding flow. However, it can be seen in fig. 11 (right column), that more small structures remain in the velocity component plots of the PsiPhi simulation, whereas the flow fields of the OpenFOAM calculation are smoother (left column fig. 11). This discrepancy is a result of the different numerical schemes: with OpenFOAM, a combination between the central difference scheme (CDS) and the total variation diminishing scheme (TVD) is applied for the momentum fluxes, inside the valve gap for Ma>0.5. By using the TVD scheme, kinetic energy partially dissipates, resulting in smoother flow fields. With PsiPhi, the momentum fluxes are discretized by the CDS scheme, resulting in less dissipation.

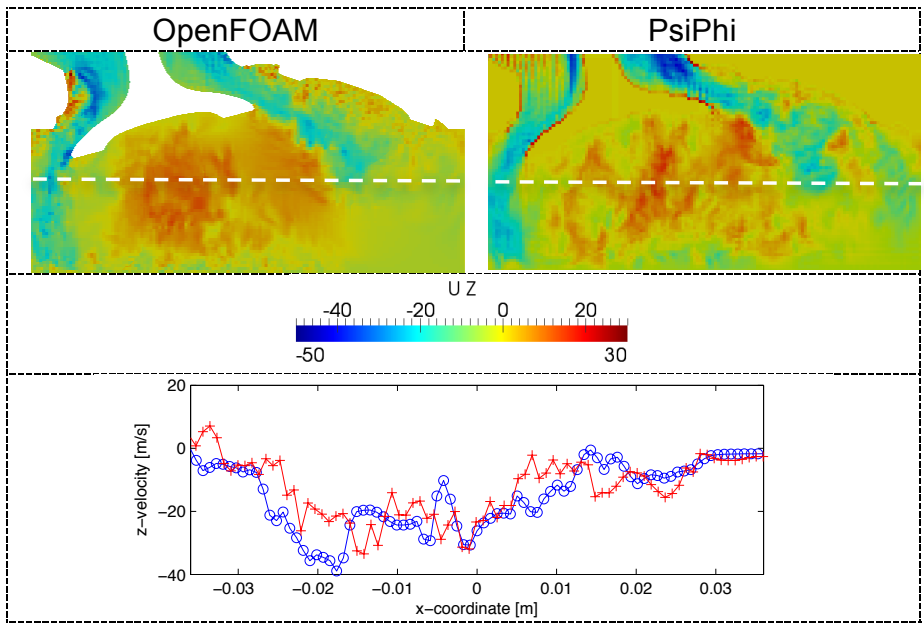

Figure 11: z-velocity component from both simulations at -310 $\mathrm{CA}^{\circ}$, at the position of the dashed white line, the velocity profile are taken (OpenFOAM (-O-), PsiPhi (-+-))

Figure 12 shows the tumble velocity profiles of the $z$ components at $10 \mathrm{~mm}$ and $30 \mathrm{~mm}$ underneath the cylinder head for both simulations and the experiment. The tumble flow velocities are qualitatively captured by both simulations. The instantaneous velocities in the lower cross-section $(30 \mathrm{~mm})$ 
at $-180 \mathrm{CA}^{\circ}$ (fig. 12) show similar flow patterns for both approaches.

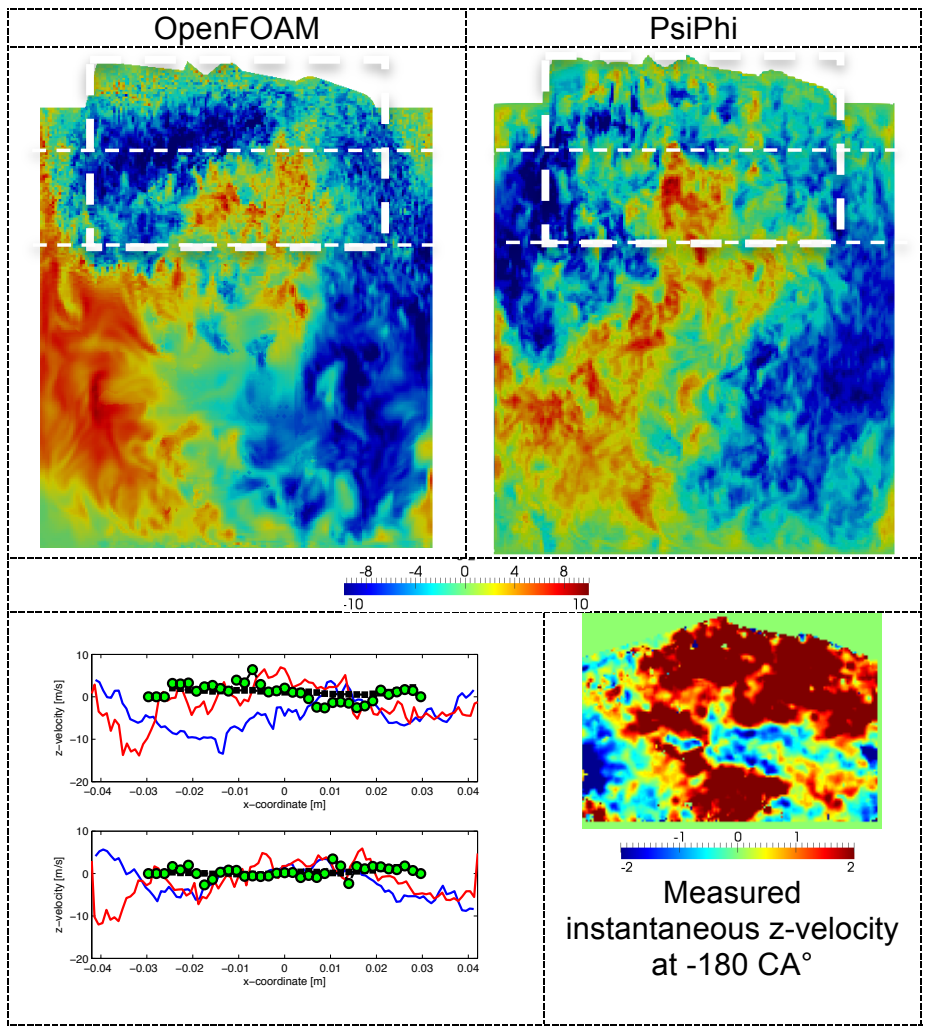

Figure 12: Comparison of the z-velocity components of both simulations at $-180 \mathrm{CA}^{\circ}$ : The white box denotes the window of the measurement at $-180 \mathrm{CA}^{\circ}$. The velocity profiles are sampled at $10 \mathrm{~mm}$ and $30 \mathrm{~mm}$ underneath the cylinder head (OpenFOAM (-), PsiPhi (-), a single, instantaneous measurement $\left({ }^{\circ}\right)$, phase-locked average over 100 cycles $(\boldsymbol{\square})$

In fig. 13, the flow field during the late compression at $-90 \mathrm{CA}^{\circ}$ is shown. The fine structures are preserved in both simulations, which imply the importance of low dissipative numerical schemes.

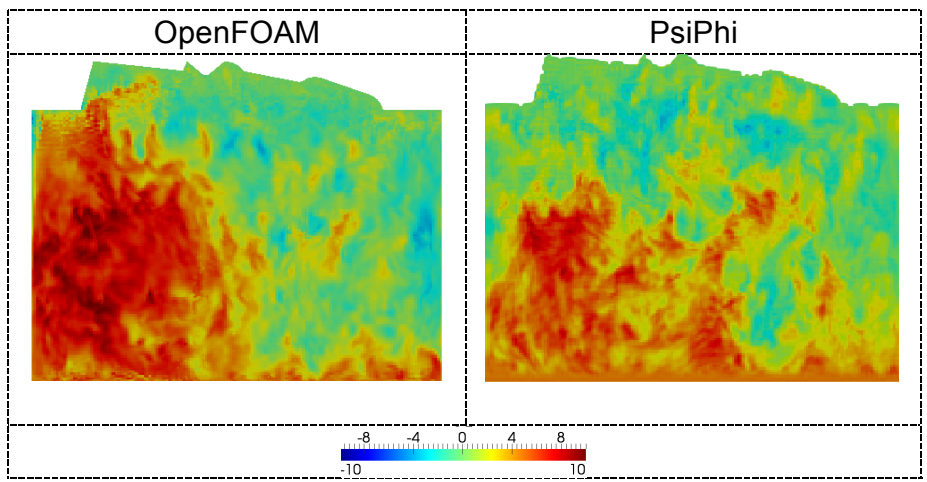

Figure 13. Comparison of the z-velocity components (in $\mathrm{m} / \mathrm{s}$ ) from both simulations at $-90 \mathrm{CA}^{\circ}$

The two-dimensional cross-sections through the cylinder volume in fig. 12 do not reveal the full extent of the inhomogeneity of the velocity field at that location. Figure 14 shows horizontal Page 8 of 13 cuts for both approaches in a plane $30 \mathrm{~mm}$ below the cylinder head at $-180 \mathrm{CA}^{\circ}$. Both approaches capture a large range of turbulent structures, with the overall field being similar.

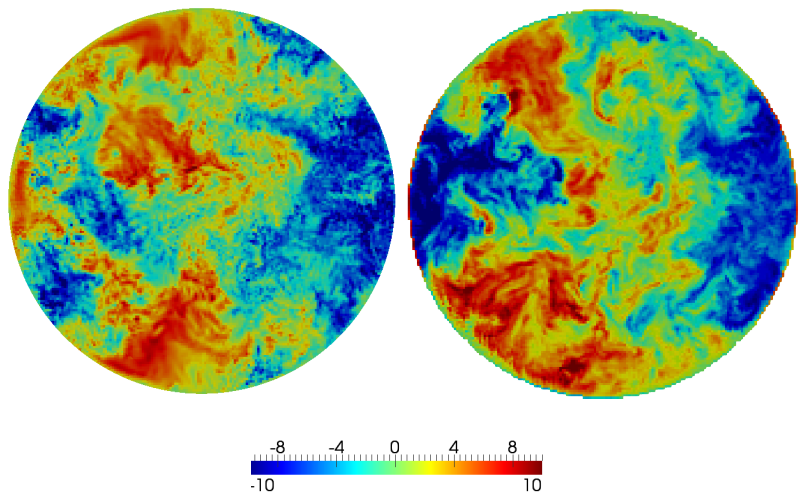

Figure 14. z-velocity in horizontal cross-section (in $\mathrm{m} / \mathrm{s}$ ), 30 $\mathrm{mm}$ below the fire deck at $-180 \mathrm{CA}^{\circ}$ (left: OpenFOAM, right: PsiPhi)

Based on this work, further investigations will be carried out for the combustion phase in SI engines. Figures 15 and 16 present preliminary results of the premixed turbulent combustion performed with OpenFoam and PsiPhi, respectively.

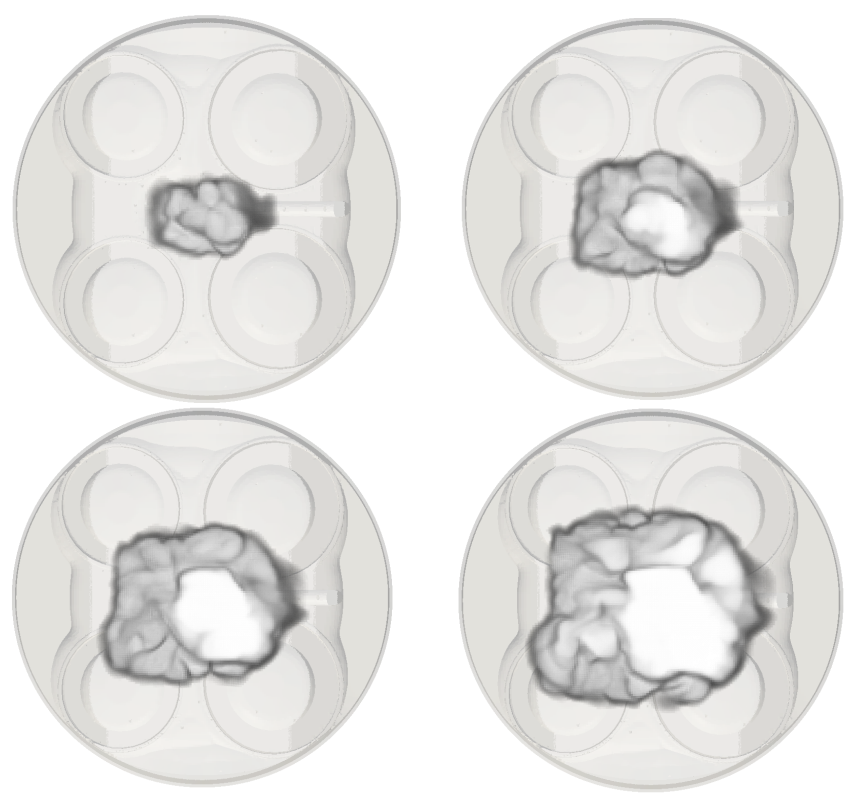

Figure 15: Volume rendering of the flame front propagation in the IVG engine (i.e., the engine that was used for comparing the cold flow in figs. 8 - 14) as seen from the top - OpenFOAM 

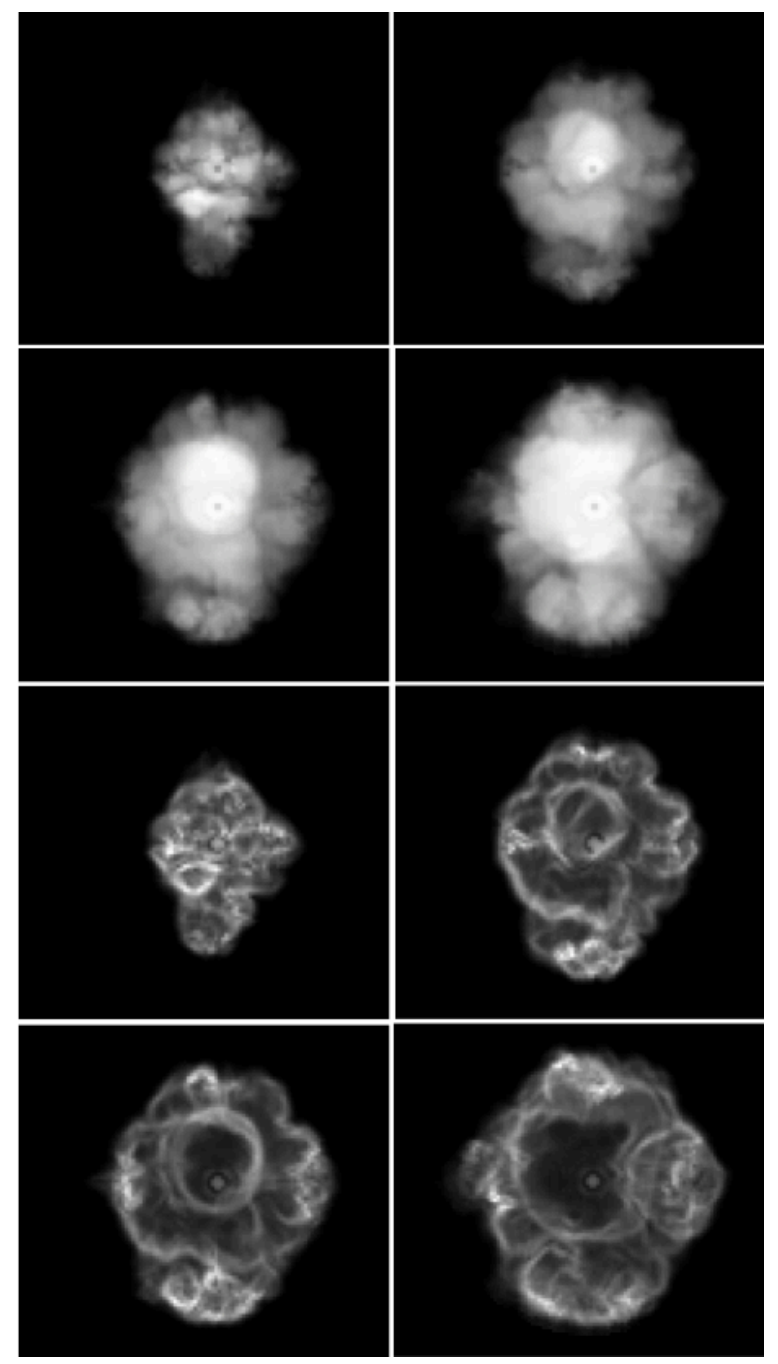

Figure 16: Volume rendering of the simulated flame propagation visualised by the progress variable (top four images) and the reaction source term (bottom four images) as seen from the top at different $\mathrm{CA}^{\circ}$ for the optical engine [9] at the Center of Smart Interfaces (CSI), Technische Universität Darmstadt PsiPhi.

\section{Conclusion}

In this paper, Large Eddy Simulation for an IC engine is studied with two different simulation tools. The simulation results show good qualitative agreement with each other and with experimental data.

Despite the differences in the meshing strategy, numerical schemes, boundary conditions and moving-mesh description, similarity of the numerical results can be observed and qualitatively compared. Similar flow patterns are obtained in the tumble flow and in the valve section at different crank angles for both simulations.

With the OpenFOAM approach, the mesh is moving within the domain, causing interpolation errors inside the domain - a problem that is avoided with PsiPhi. On the other hand, Open-
FOAM can achieve better resolution within the valve gap due to the local mesh refinement. Using a central differencing scheme for the momentum transport with Mach-number dependent blending to TVD, both approaches achieve little numerical oscillation and manage to resolve relatively small turbulent structures throughout the computational domain.

Whereas PsiPhi is fast because of its simplicity and optimization for modern hardware, OpenFOAM achieves a similar calculation time as the fully compressible scheme is replaced by the PISO scheme and a much bigger CFL number is used. The meshing of the geometry is automated in both approaches, such that the preparation of the setup files takes less than one personnel hour for each approach, starting out from an existing STL file. With PsiPhi, grid-generation completes within minutes, whereas with OpenFOAM, it takes around $2000 \mathrm{CPU}$ hours for the geometry presented here, contributing roughly $10 \%$ to the computational cost for a single cycle. However, also with OpenFOAM the simulation can be started within one hour, i.e., as soon as the first grid has been generated.

\section{References}

1. OpenCFD. OpenCFD release OpenFOAM, 2013

2. Kempf, A. M., Geurts,B., and Oefelein,J. C.,"Error analysis of large-eddy simulation of the turbulent non-premixed Sydney bluff-body flame," Combust. Flame, vol. 158, pp. 2408-2419, 2011.

3. Thuong, N. M., Kempf, A. M.,"Large eddy simulation of an IC engine: An approach for moving boundaries in IC engine simulations," Proceedings of the European Combustion Institute, vol. 6, 2013.

4. Peskin,C. S., " Flow patterns around heart valves: a numerical method," Journal of Computational Physics, 1972,10:220252.

5. Moureau, V., Barton, I., Angelberger, C.andPoinsot, T.,"Towards large eddy simulation in internal-combustion engines: simulation of a compressed tumble flow," SAE Paper (2004-01-1995).

6. Vermorel, O., Richard, S., Colin, O.,Angelberger, C., Benkenida, A.and Veynante, D.,"Towards the understanding of cyclic variability in a spark ignited engine using multicycle LES," Combustion and Flame, 156(8), 1525-1541

7. Sone, K. and Menon, S.,"Effect of subgrid modeling on the in-cylinder unsteady mixing process in a direct injection engine," Journal of engineering for gas turbines and power, 125(2), 435-443.

8. Mohamed Ismail, H., Ng, H. K. and Gan, S.,"Evaluation of non-premixed combustion and fuel spray models for incylinder diesel engine simulation," Applied Energy, 90(1), 271-279.

9. Baumann, M., di Mare, F.and Janicka, J.,"On the Validation of Large Eddy Simulation Applied to Internal Combustion Engine Flows Part II: Numerical Analysis," Flow, Turbulence and Combustion, 1-19.

10. Smagorinsky, J., Mon. Wea. Rev., 91 (1963) 99164.

11. Janas, P., Schild, M.,Kaiser, S., Kempf, A.,"Numerical simulation of flame front propagation in a spark ignition engine,"Proceedings of the European Combustion Institute, vol. 6, 2013.

12. Lucchini, T., Fiocco, M., Onorati, A., Montanaro, A. et al., "Full-Cycle CFD Modeling of Air/Fuel Mixing Process in an Optically Accessible GDI Engine," SAE Int. J. Engines 6(3):1610-1625, 2013, doi:10.4271/2013-24-0024. 
13. Contino, F., Lucchini, T., D'Errico, G., Duynslaegher, C. et al., "Simulations of Advanced Combustion Modes Using Detailed Chemistry Combined with Tabulation and Mechanism Reduction Techniques," SAE Int. J. Engines 5(2):185-196, 2012, doi:10.4271/2012-01-0145.

14. Lucchini, T., D’Errico, G., Ettorre, D., and Ferrari, G., "Numerical Investigation of Non-Reacting and Reacting Diesel Sprays in Constant-Volume Vessels," SAE Int. J. Fuels Lubr. 2(1):966-975, 2009, doi:10.4271/2009-011971.

15. Lucchini, T., D'Errico, G., Onorati, A., Bonandrini, G. et al., "Development of a CFD Approach to Model Fuel-Air Mixing in Gasoline Direct-Injection Engines," SAE Technical Paper 2012-01-0146, 2012, doi:10.4271/2012-01-0146.

16. Jasak,H. and Tuković,Ž.,"Automatic Mesh Motionfor the Unstructured Finite Volume Method," Transactions of FAMENA, 30 (issue 2), 2007.

17. Issa,R. I.,"Solution of the Implicit Discretized Fluid Flow Equations by Operator Splitting. Mechanical Engineering," Rep. FS-82-15, 1982.

18. Marcantoni, L. F. G., Tamagno, J. P., Elaskar,S. A., "High Speed Flow Simulation Using OpenFOAM," MecanicaComputacional Vol XXXI (2012) 2939-2959.

19. Sweby, P.K., "High resolution schemes using flux-limiters for hyperbolic conservation laws," SIAM J. Num. Anal. 21 (5): 995-1011, Bibcode:1984SJNA...21..995S, doi:10.1137/0721062, 1984

20. Ma,T., Stein, O., Chakraborty, N., Kempf, A. M.,"Aposteriori testing of algebraic flame surface density models for LES," Combustion Theory and Modelling, 2013.

21. Pettit,M.,Coriton, B., Gomez, A. and Kempf,A. M.,"Largeeddy simulation and experiments on non-premixed highly turbulent opposed jet flows," Proc. Combust. Inst.,vol. 33, pp. 1391-1399, 2011.

22. Olbricht,C., Stein, O. T., Janicka,J., van Oijen J. A., Wysocki, S. and KempfA. M.,"LES of lifted flames in a gas turbine model combustor using top-hat filtered PFGM chemistry," Fuel, vol. 96, pp. 100-107, 2012.

23. Rittler,A.,Proch,F. and Kempf,A. M.,"Large eddy simulation of the Sydney piloted spray burner," Proceedings of the European Combustion Meeting, vol. 6, 2013.

24. Franchetti,B. M.,Marincola,F. C., Navarro-Martinez,S. and Kempf, A. M.,"Large eddy simulation of a pulverised coal jet flame," Proc. Combust. Inst., 2013.

25. Poinsot,T. J.,Lele,S. K., "Boundary Condition for Direct Simulations of Compressible Viscous Flows," Journal of Computational Physics 101, 14-129 (1992).

26. Roth,G. I. and Katz,J.,"Five techniques for increasing the speed and accuracy of PIV interrogation," Meas. Sci. Technol. 12 238-245, 2001.

\section{Contact Information}

For information regarding OpenFOAM, please contact Peter Janas (peter.janas@uni-due.de), Tommaso Lucchini (tommaso.lucchini@polimi.it) or Andreas Kempf (andreas.kempf@uni-due.de). For questions related to PsiPhi, please address Thuong Nguyen (nguyen.thuong@uni-due.de) or Andreas Kempf (andreas.kempf@uni-due.de). Please write to
Sebastian Kaiser (sebastian.kaiser@uni-due.de) for information on the experiments.

\section{Acknowledgments}

The authors acknowledge the financial support by the state of NRW, Germany. Furthermore, we would like to thank the Center for Computational Sciences and Simulation (CCSS) of Duisburg-Essen University for providing the computational resources.

\section{Definitions/Abbreviations}

\begin{tabular}{|c|c|}
\hline BDC & Bottom Dead Center \\
\hline CDS & $\begin{array}{l}\text { Central Difference } \\
\text { Scheme }\end{array}$ \\
\hline $\mathrm{CA}^{\circ}$ & Crank Angle Degree \\
\hline IVG & $\begin{array}{l}\text { Institute for Combus- } \\
\text { tion and Gasdynamics }\end{array}$ \\
\hline IVC & Intake Valve Closed \\
\hline LES & Large Eddy Simulation \\
\hline LODI & $\begin{array}{l}\text { Local One Dimension- } \\
\text { al Inviscid }\end{array}$ \\
\hline NSCBC & $\begin{array}{l}\text { Navier-Stokes Charac- } \\
\text { teristic Boundary Con- } \\
\text { dition }\end{array}$ \\
\hline OpenFOAM & $\begin{array}{l}\text { Open Field Operation } \\
\text { and Manipulation }\end{array}$ \\
\hline PIV & $\begin{array}{l}\text { Particle Image Veloc- } \\
\text { imetry }\end{array}$ \\
\hline STL & Stereo Lithography \\
\hline TDC & Top Dead Center \\
\hline TVD & $\begin{array}{l}\text { Total Variation Dimin- } \\
\text { ishing }\end{array}$ \\
\hline U-RANS & $\begin{array}{l}\text { Unsteady Reynolds } \\
\text { Averaged Navier- } \\
\text { Stokes }\end{array}$ \\
\hline
\end{tabular}




\section{Appendix}

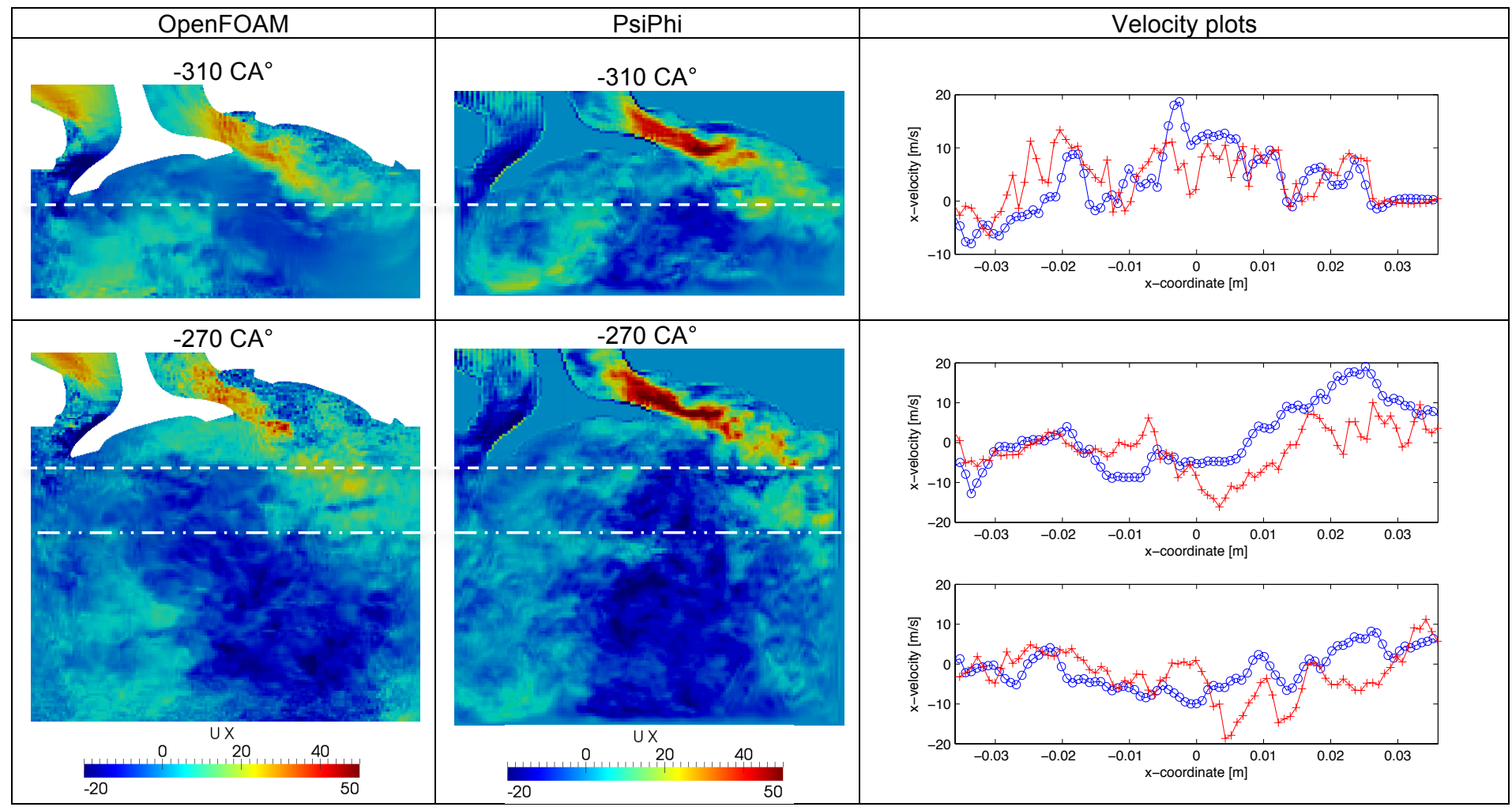

Figure 17:Contour plots of the x-velocity component in a cut through the intake valve for $-310 \mathrm{CA}^{\circ}$ and $-270 \mathrm{CA}^{\circ}$ and the corresponding velocity profiles for $10 \mathrm{~mm}(--)$ and $30 \mathrm{~mm}(-\bullet-)$ below the cylinder head.

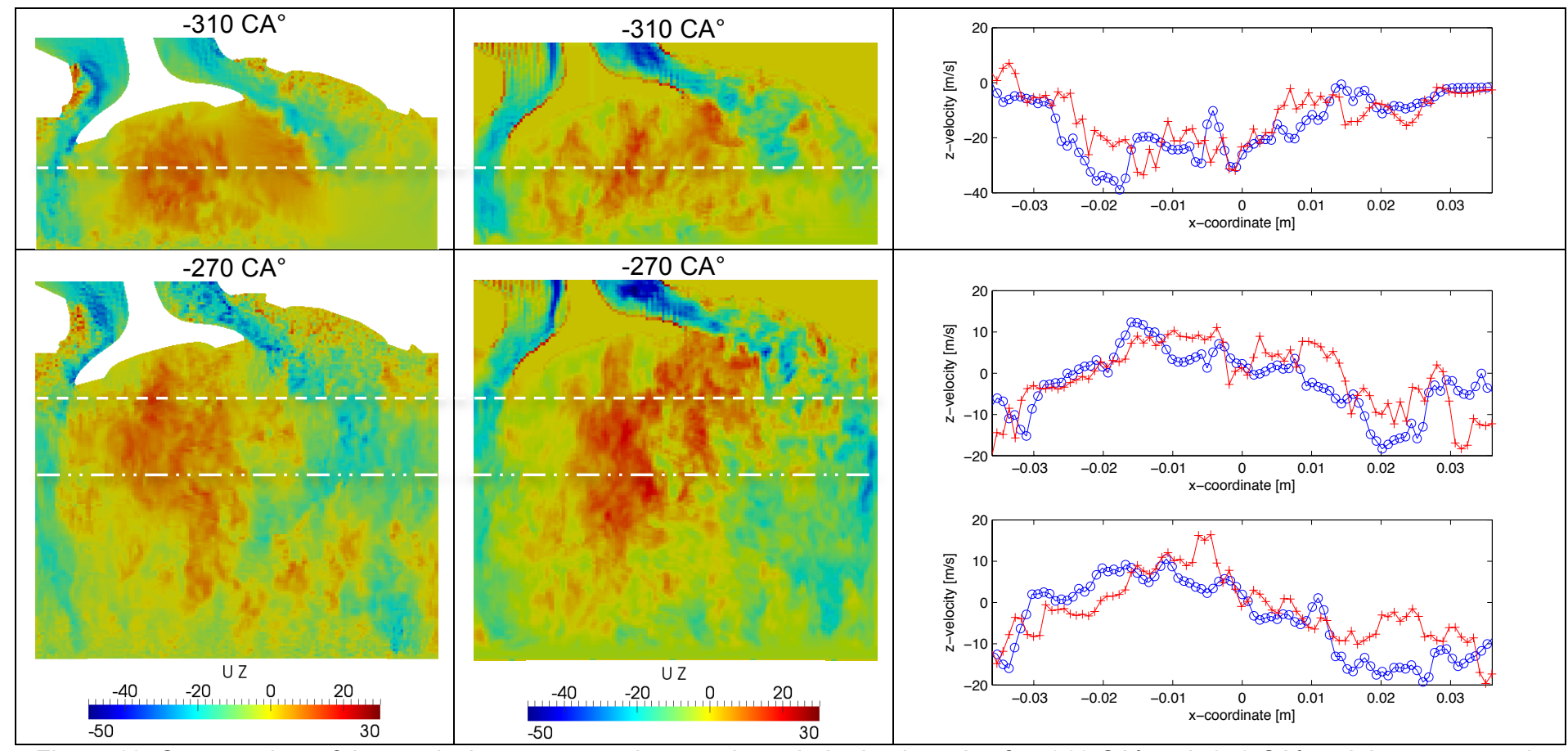

Figure 18: Contour plots of the z-velocity component in a cut through the intake valve for $-310 \mathrm{CA}^{\circ}$ and $-270 \mathrm{CA}^{\circ}$ and the corresponding velocity profiles for $10 \mathrm{~mm}(--)$ and $30 \mathrm{~mm} \mathrm{(- \bullet -)} \mathrm{below} \mathrm{the} \mathrm{cylinder} \mathrm{head.}$ 


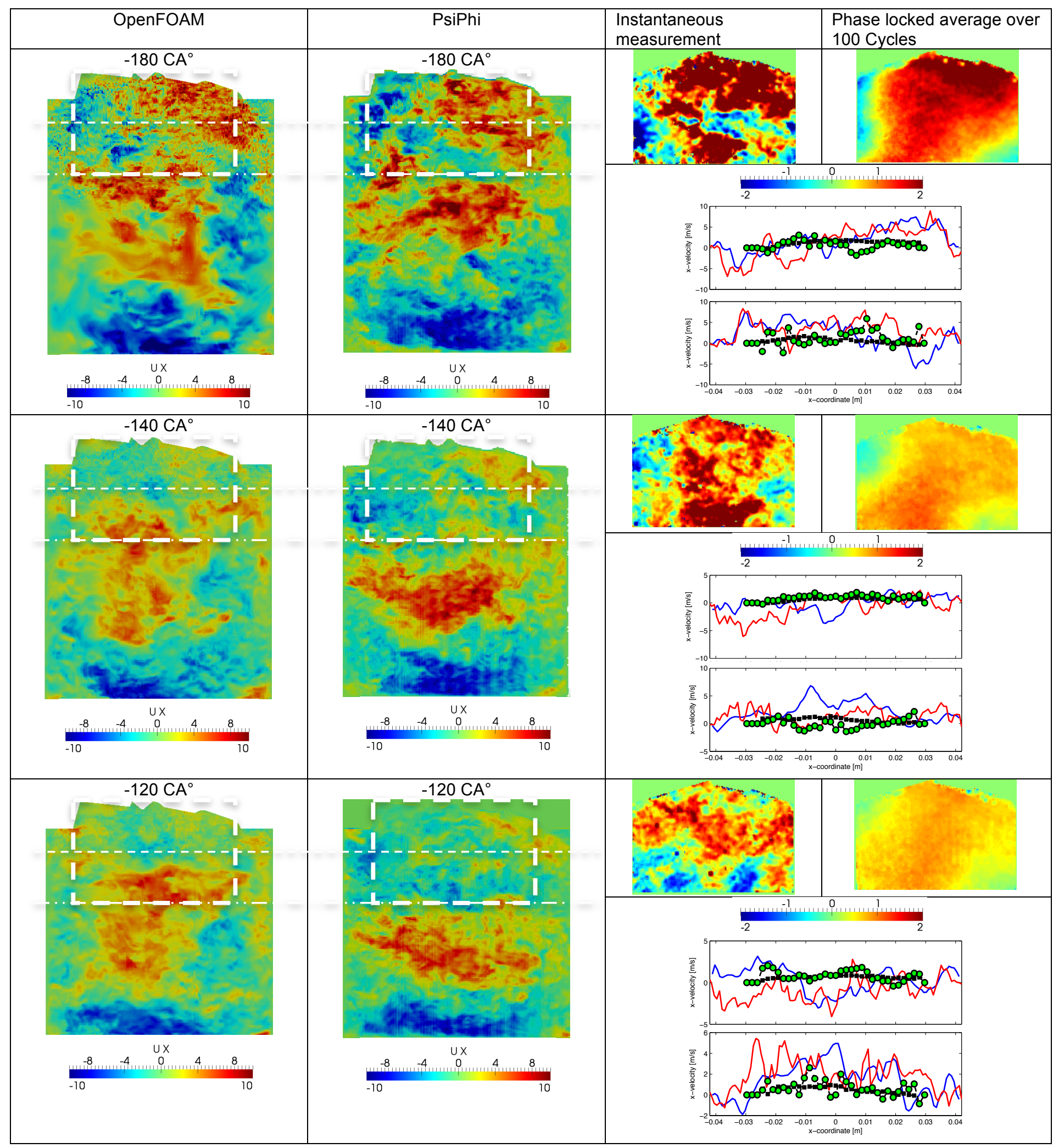

Figure 19: Contour plots of the x-velocity component of the tumble symmetry plane for $-180 \mathrm{CA}^{\circ},-140 \mathrm{CA}^{\circ}$ and $-120 \mathrm{CA}^{\circ}$. Velocity profiles are sampled for $10 \mathrm{~mm}(--)$ and $30 \mathrm{~mm}(-\bullet-)$ below the cylinder head. The white dashed box corresponds to the area of the measurement. One measured instantaneous velocity contour plot is shown and the phase locked average from 100 cycles. OpenFOAM (-), PsiPhi (-), instantaneous measurement ( $\left.{ }^{\circ}\right)$, phase-locked average over 100 cycles (ם) 


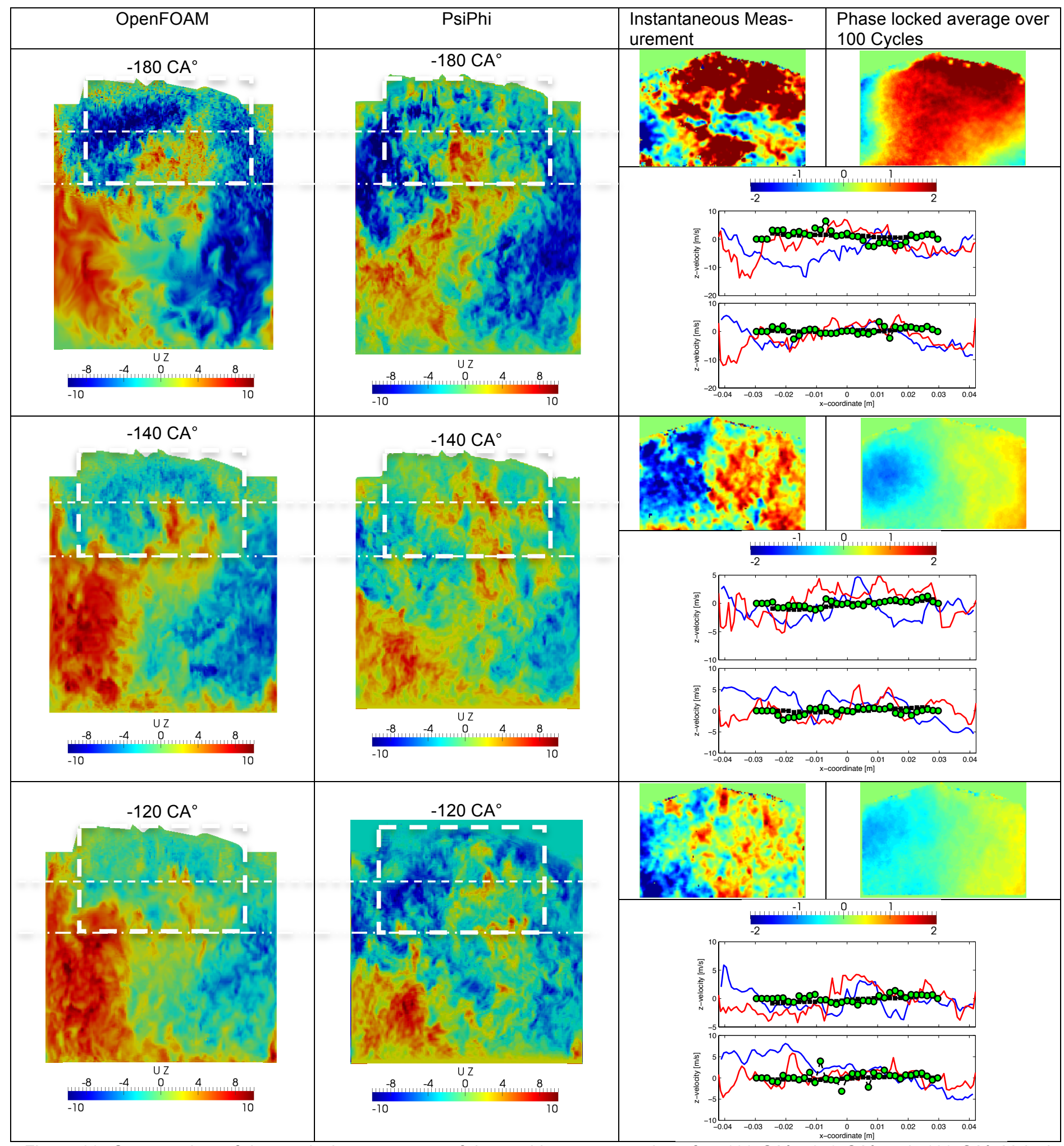

Figure 20: Contour plots of the z-velocity component of the tumble symmetry plane for $-180 \mathrm{CA}^{\circ},-140 \mathrm{CA}^{\circ}$ and $-120 \mathrm{CA}^{\circ}$. Velocity profiles are sampled for $10 \mathrm{~mm}(--)$ and $30 \mathrm{~mm}(-\bullet-)$ below the cylinder head. The white dashed box corresponds to the window of the measurement. One measured instantaneous velocity contour plot is shown and the phase locked average from 100 cycles. OpenFOAM (-), PsiPhi (-), instantaneous measurement $\left({ }^{\circ}\right)$, phase-locked average over 100 cycles (ם). 